\title{
Experience in endoscopic stapedotomy technique and its audiological outcome: a case series
}

\author{
Nazik E. Abdullah' ${ }^{1 *}$, Tarig A. Nafie², Ahmed F. Mohammed ${ }^{3}$, Alwaleed A. Abdelmomin ${ }^{3}$, Hashim I. Yagi ${ }^{1}$ and \\ Azza M. Ahmed ${ }^{3}$
}

\begin{abstract}
Background: Stapedotomy is being performed endoscopically for otosclerosis in Sudan since 2011 with increasing number of patients. This prospective hospital-based study from Nov 2016 to Nov 2020 states the clinicdemographic features of otosclerosis; it describes this surgical technique and hearing outcome following endoscopic stapedotomy.

Results: Total number included in the study was 91 patients. Females were 48, and males were 43 with a female to male ratio of 1.1:1. Age ranged from 19 years to 52 with a mean age of 30.6 7 SD years. The main symptom was decreased hearing in all patients (100\%); in 82 patients (90\%), it was bilateral, followed by tinnitus in 80 patients (88\%) while two patients (2.2\%) had vertigo. Family history was stated by 2 patients (2.2\%) only. Audiological assessment by pure tone audiogram (PTA) for each ear (total of 182) revealed that conductive hearing loss (CHL) is the commonest type of hearing loss in 148 ears (81.3\%), mixed type in 30 ears (16.5\%), while 4 ears (2.2\%) were normal.

Endoscopic stapedotomy was performed for 74 patients; this technique was safe; few complications were managed successfully: one gusher and one revision, with no facial nerve injury. Majority of complications happened during the first year. Mean air bone gap (ABG) gain was $23.3 \pm 7.2 \mathrm{~dB}$, air conduction (AC) gain was $18.3 \pm 8 \mathrm{~dB}$, and Carhart notch disappeared in 79.5\%.
\end{abstract}

Conclusions: Endoscopic stapedotomy is a safe and effective procedure with a steep learning curve and a satisfactory hearing outcome. The air bone gap (ABG) gain was comparable to international studies.

Keywords: Stapedotomy, Endoscopic, Otosclerosis, Audiological, Outcome

\section{Background}

Otosclerosis is a disease of the otic capsule, characterized by bone remodeling that affects the stapediovestibular joint, only when stapes movement becomes compromised with consequent conductive hearing loss, clinical otosclerosis is designated $[1,2]$. Histological otosclerosis is more prevalent and may remain asymptomatic [3]. When the otosclerotic focus reaches the

\footnotetext{
* Correspondence: nazikfad1223@yahoo.co.uk

1 Department of Otorhinolaryngology H\&N Surgery, Faculty of Medicine,

University of Khartoum, P O Box102, Qasr Street, Khartoum, Sudan

Full list of author information is available at the end of the article
}

cochlear endosteum, sensory hearing loss ensues, and a mixed type of otosclerosis is defined [4].

Clinically, the main symptom is progressive conductive hearing loss, it occurs bilaterally in $70-80 \%$ of the cases, nearly $68 \%$ of the patients report tinnitus, and $10 \%$ experience vertigo $[5,6]$. The clinical form of otosclerosis is more common in women than in men; interestingly, in the histological form of the disease, the ratio between women and men was found to be 1:1 [7]. The average age of onset is in the thirties [6]. Otosclerosis is one of the most common causes of adult-onset hearing loss in the Caucasian population, where it has a prevalence of 
$0.3-0.4 \%$; its prevalence is lower in Blacks, Asians, and Native Americans [8].

Regarding pathophysiology, viral infection and hormones have been implicated; however, the obvious ethnic predisposition suggests that genetic components play a major role in disease pathogenesis. Additional evidence to support the role of genetics includes familial inheritance studies that to date have identified eight different otosclerosis loci (OTSC1-8). Population-based casecontrol studies have also associated a number of genes with otosclerosis. Sporadic and familial forms are nearly equal in incidence [9].

Stapes surgery for restoration of sound transmission through the ossicular chain is considered the mainstay of treatment of conductive-type hearing loss in otosclerosis; other options include observation and hearing aid [10]. There is no treatment for the sensorineural component of the disease; however, cochlear implantation for individuals with profound hearing loss due to otosclerosis has been effective [11]. Stapedotomy is considered as a successful surgery in terms of hearing improvement. Complications, such as total sensorineural hearing, facial nerve palsy, and perilymph fistula, could occur at different rates [12].

The steps of the contemporary stapedotomy were described first by Fisch; they can be simplified as removal of the supra-structure of the stapes followed by opening part of the stapes footplate. A prosthesis is fitted into the opening made in the footplate, connecting the incus to the oval window and restoring ossicular conduction by bypassing the fixed footplate [13]. The footplate fenestration of the stapedotomy procedure is now a distant reminder of semicircular canal fenestration [14].

Classically, stapes surgery is performed using the microscope; however, use of endoscope in ear surgery including stapedotomy is gaining popularity [15].

Stapedotomy started to be performed endoscopically for otosclerosis in specialized ENT hospitals in Sudan since 2011 with increasing number of patients, while stapes surgery using the microscope is merely performed by visiting consultant surgeons infrequently.

This study aims at addressing the clinicodemographic features of otosclerosis in the studied group of patients; it describes the technique of endoscopic stapedotomy and reviews the audiological outcome of this technique.

\section{Methods}

A prospective hospital-based study during the period Nov 2016 to Nov 2020 was conducted in ENT Khartoum Teaching Hospital and Aldoha Specialized ENT Hospital. All patients who were diagnosed as otosclerosis based on clinical and audiological assessment were included in the study. Patients are informed verbally about the study and signed an informed consent to participate in this study. Ethical clearance was obtained from the Research Committees of the mentioned Hospitals. Demographic data was reported. The same inclusion criteria were applied for the studied patients in both hospitals.

\section{Audiological assessment}

Hearing assessment included pure tone audiogram (PTA), tympanometry, and stapedial reflex for all patients, while speech discrimination test was selectively done for patients with mixed hearing loss. High resolution CT scan of the temporal bone is requested when the clinical and/or audiological data questions the diagnosis of otosclerosis, e.g., congenital hearing loss. Each patient's threshold for air conduction $(\mathrm{AC})$, bone conduction $(\mathrm{BC})$, and air bone gap (ABG) at frequencies 0.5 , 1,2 , and $4 \mathrm{kHz}$ were reported before and after surgery. The mean preoperative and post-operative $\mathrm{AC}, \mathrm{BC}$, and ABG were also calculated. For the test of significance, we used paired $t$ test, and $P$ value was considered significant if $P<0.05$.

\section{Surgical technique}

The principles of stapedotomy were described earlier in the "Background" section [13]; they are the same whether using an endoscope or a microscope; the basic difference is that in an endoscopic technique a single hand is operating as the other hand holds the endoscope, whereas in the microscopic, two hands are operating.

Four surgeons performed endoscopic stapedotomy with the same technique for all studied patients; the same surgeons operated on patients in both hospitals. Endoscopic stapedotomy was performed using the endoscopes of $18-\mathrm{cm}$ length, 4-mm diameter, and $0^{\circ}$ and $30^{\circ}$ lenses. The endoscope was held with the left hand in the case of right-handed surgeon.

Surgery was performed under local anesthesia, infiltration of $2-5 \mathrm{ml}$ of lignocaine with adrenaline 1:200,000 by cannula (size 22) in the external canal skin, $2-3 \mathrm{~mm}$ lateral to the junction between hairy and non-hairy skin at 6 and 12 o'clock positions; intravenous analgesia (paracetamol infusion) is administered during the surgical procedure; in few patients, the operation was done under general anesthesia. The endomeatal incision was placed on the external canal wall 5-7 $\mathrm{mm}$ lateral to the tympanic annulus from 12 o'clock position to 6 o'clock position; a swab was applied beneath the round knife to protect the flap and make the field clear off blood. The tympanomeatal flap was elevated; posterior scutum bone was partially removed with a curette to expose the oval window and the stapes. Mobility of the stapes was checked by a hook, elevating the incus very gently; another test was used by applying few drops of normal 
saline to the round window niche; if the foot plate of the stapes was fixed, no movement would be observed on the surface of saline and appears as static light reflection and vice versa, this test could give false impression of stapes fixation if the round window was hidden beyond a prominent niche. After separating the incudostapedial joint with a joint knife and cutting the stapedial tendon, the posterior crus of the stapes was divided with a scissor. The anterior crus of stapes was subsequently downfractured with a micro hook and removed. The prosthesis was sized by measuring the distance from the footplate to the long process of the incus. A fenestra of $0.7 \mathrm{~mm}$ in diameter was made by a perforator (micro pick); middle and posterior part of footplate are typically preferable sites of fenestration. Teflon piston prosthesis $0.6 \mathrm{~mm}$ in diameter was used in all cases and positioned after adjustment of its length, encircled over long process of incus and interpositioned in footplate fenestration. Fenestration sealing was done either with lobule fat after prosthesis insertion or with vein graft before insertion of prosthesis, finally, reposition of tympanomeatal flap and placement of gelfoam piece on top of it, medial to the endomeatal incision. On table, subjective hearing improvement was checked. A check list was used to assess this technique by review of recorded surgical videos. The checklist included tympanomeatal flap elevation, integrity of tympanomeatal flap, scutum removal, section of stapedius tendon, separation of incudostapedial joint, fracture of crura, fenestration of foot plate, and insertion of prosthesis.

Dexamethasone $8 \mathrm{mg}$ iv was given at the beginning of surgery, then 8 hourly for 24 h routinely, while cinnarizine was prescribed only for postoperative dizziness.

\section{Results}

Total number included in the study was 91 patients. Females were 48 , and males were 43 with a female to male ratio of 1.1:1. Age ranged from 19 years to 52 with a mean age of $30.6 \pm 7 \mathrm{SD}$ years. The main symptom was decreased hearing in all patients (100\%); in 82 patients $(90 \%)$ it was bilateral, followed by tinnitus in 80 patients $(88 \%)$ while two patients $(2.2 \%)$ had vertigo. Family history was stated by 2 patients (2.2\%) only. No patient was fitted before with hearing aid. All patients in this study did have normal tympanic membrane on otoscopic examination. Schwartz sign was not observed in any patient.

Audiological assessment by pure tone audiogram (PTA) for each ear (total of 182) revealed that conductive hearing loss (CHL) is the commonest type of hearing loss in 148 ears (81.3\%), mixed type in 30 ears (16.5\%), while 4 ears $(2.2 \%)$ were normal. Tympanometry results are as follows: type A was the most frequent, it was

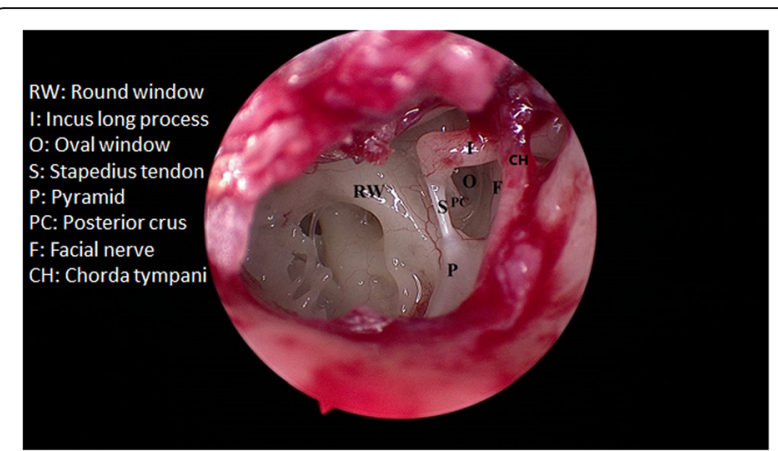

Fig. 1 Endoscopic view of the middle ear during stapedotomy, using $0^{\circ}$ endoscope. Note exposure of oval window $(\mathrm{O})$ at foot plate of the stapes

reported in 127 ears (69.8\%), type As in 55 ears (30.2\%), none of the ears were type B or type C.

Regarding patient's choices for treatment modality after careful examination, audiological assessment, and counseling regarding the diagnosis, prognosis, options of treatment, and possible complications, surgery was chosen by 80 patients $(88 \%)$ after exclusion of the contraindications of surgery, while 6 patients (7.6\%) preferred the option of using a hearing aid. Five patients (5.5\%) were advised to use hearing aids as the suitable option for hearing solution; they had mixed hearing loss with moderate to severe sensory element.

Of the eighty patients who were planned for stapedotomy, two patients were excluded later on. In one patient, deformed ossicular chain was anticipated according to $\mathrm{CT}$ and confirmed by the presence of non-ossified ossicles, and the other one had abnormal laying facial nerve over the oval window; CT was not performed preoperatively for this case; consequently, stapedotomy was condemned after tympanotomy. Four of the scheduled patients for surgery did not attend.

Endoscopic stapedotomy was performed for 74 patients, as a primary procedure for 73 patients (98.6\%) and as revision for 1 patient (1.4\%). Duration of surgery was $46 \pm 13 \mathrm{SD}$ min. Exposure of middle ear during

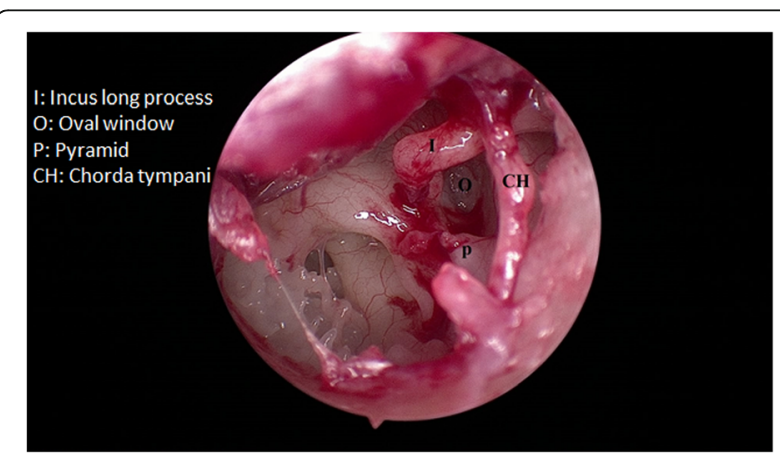

Fig. 2 Oval window $(\mathrm{O})$ exposed after stapes' crura fracture 


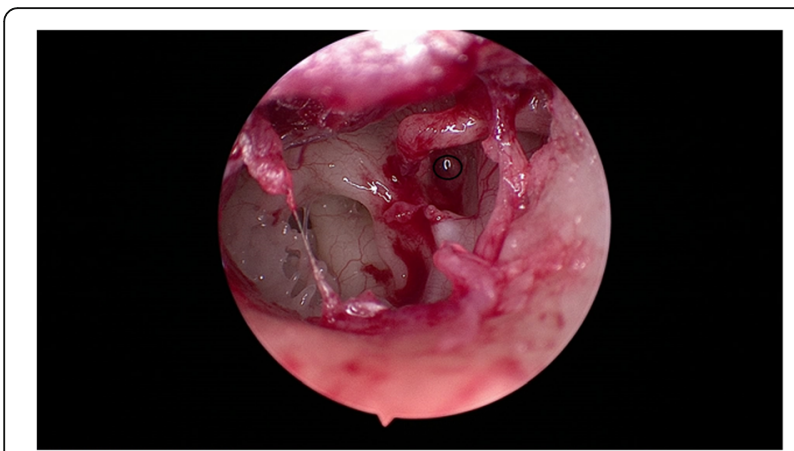

Fig. 3 Stapedotomy (fenestration) being performed at the center of the black circle

stapedotomy and prosthesis insertion is demonstrated in Figs. 1, 2, 3, and 4.

Summary of surgical steps and procedure-associated complications over the 5 years of the study and how they were managed are presented in Table 1.

Audiometric tests were performed at 45 to 60 days, 6 months, and 1 year, postoperatively, follow-up ranged from 6 to 30 months, with a mean of $18 \pm 6$ SD months. The overall mean preoperative hearing threshold (AC) was $43.1 \pm 9.0 \mathrm{SD} \mathrm{dB}$, while the overall mean postoperative hearing threshold was $24.8 \pm 7.1 \mathrm{SD} \mathrm{dB}$; hearing (AC) threshold gain was $18.3 \pm 8.0 \mathrm{SD} \mathrm{dB}$. Details of AC at different frequencies before and after stapedotomy are illustrated in Table 2.

Preoperative overall mean $\mathrm{BC}$ value was $21.5 \pm 11.0 \mathrm{SD}$ $\mathrm{dB}$, and postoperative overall mean $\mathrm{BC}$ was $18.7 \pm 7.2 \mathrm{SD}$ $\mathrm{dB}$; this difference was found to be statistically significant ( $p$ value $<0.050$ ). Carhart notch (dip in bone conduction at $4 \mathrm{KHz}$ ) was seen in 44 ears out of $74(59.4 \%)$ on preoperative audiological assessment, while after stapedotomy it disappeared in 35 ears (79.5\% of Carhart positive ears).

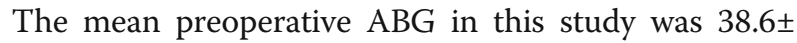
9.8 $\mathrm{SD} \mathrm{dB}$, and the mean postoperative ABG was $15.3 \pm$ 4.2 SD dB; this finding showed improvement of the ABG with $\mathrm{ABG}$ gain of $23.3 \pm 7.2 \mathrm{SD} \mathrm{dB}$. Details of $\mathrm{ABG}$ at different frequencies are presented in Table 2.

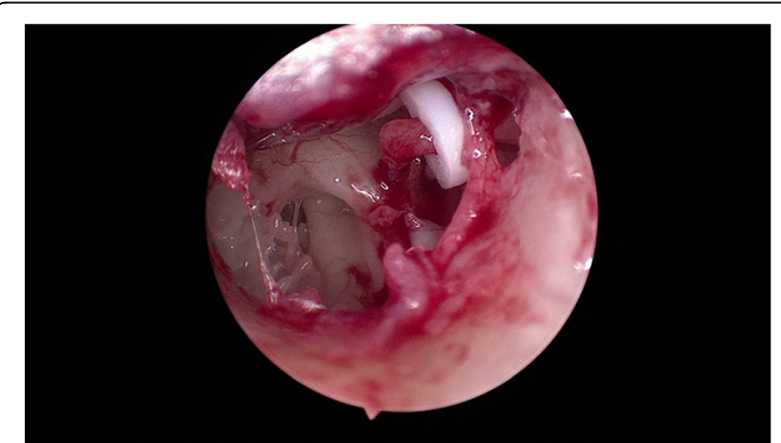

Fig. 4 Teflon prosthesis is inserted, loop around the long process of incus, and base of the shaft at stapedotomy site
Tinnitus was present in 65 patients out of $74(87.8 \%)$; in postoperative assessment, 14 patients $(21.5 \%)$ became free of tinnitus while 51 patients $(78.5 \%)$ showed no improvement. Three patients (4\%) had mild new postoperative tinnitus.

Three patients $(4.05 \%)$ developed transient postoperative vertigo, which was successfully managed by cinnarizine in 2 patients. The third patient required revision surgery; details of this revision are included in Table 1.

\section{Discussion}

Analysis of the clinical and demographic data of the studied 91 patients of otosclerosis showed that it is consistent with the literature in the following: slight predominance of females, age at presentation (mean age $30.6 \pm 7$ SD years), and bilateralism of disease (90\%). Dissimilar to many studies in high percentage of tinnitus $(88 \%)$ and absence of family history in the majority, family history was reported in only two patients $(2.8 \%)$ [57]. Although the sample size is small, we may hypothesize that the sporadic form of the disease is more prevalent than familial form, and a higher incidence of tinnitus is characteristic features of otosclerosis among our studied group of patients. A larger scale study is required to verify these two factors.

Endoscopic stapedotomy has a learning curve as the operative time and intraoperative complications became less with experience. Appreciated advantage of utilization of the endoscope is the changing scenes during instrumentation; the surgeon can change the view, magnification, and angles every fraction of a second while operating by moving the endoscope; the angled endoscopes provide clear views of middle ear structures and recesses.

Tear of tympanomeatal flap happened during the first year only, it is learned that avoidance of this complication is by adequate infiltration of the external auditory canal, keeping dissection close to the bone during elevation of the flap, use of a swab beneath the round knife, and elevation of the annulus from 6 o'clock at first where the bony rim is present up to 12 o'clock at the end against Notch of Rivinus. Adequate flap length is important to avoid short flap at the end of surgery, 5-7 $\mathrm{mm}$ lateral to the annulus gives sufficient length. Immediate repair of tympanomeatal flap was done by perichondrium; other options used when the defect was very small were fat lobule or vein graft.

Scutum removal should be tailored according to the anatomy of each patient; it should be removed to allow not only visualization of the oval window and stapes structures but to allow instrumentation as well. The surgeon must not be misled by the panoramic view provided by the endoscope, especially when using the angled one and under-remove that part of the scutum 
Table 1 Surgical steps of endoscopic stapedotomy for 74 patients, complications, and associated interventions during the 5 years (2016-2020) of the study. IS incudostapedial joint, 1ry primary, ABG air bone gap

\begin{tabular}{|c|c|c|c|}
\hline Procedure/structure & $\begin{array}{l}\text { Associated complication/ } \\
\text { finding }\end{array}$ & $\begin{array}{l}\text { Incidence during the } \\
5 \text { years of the study }\end{array}$ & Management of complications and remarks \\
\hline $\begin{array}{l}\text { Tympanomeatal flap elevation: } \\
\text { intact flap in } 70 \text { patients (94.6\%) }\end{array}$ & Tear in 4 patients $(5.4 \%)$ & 1st year & Grafted by: perichondrium, fat, or vein graft \\
\hline \multirow[t]{2}{*}{$\begin{array}{l}\text { Scutum curette: performed for } 65 \\
\text { patients (87.8\%) }\end{array}$} & Inadequate in 3 patients (4.05\%) & 1 st and 2 nd years & $\begin{array}{l}\text { Prolongation } 11 \text { min of surgery as re-curette was } \\
\text { required }\end{array}$ \\
\hline & $\begin{array}{l}\text { Over removed in } 1 \text { patient } \\
(1.4 \%)\end{array}$ & 1st year & Shortened flap, supported by thin tragal cartilage \\
\hline $\begin{array}{l}\text {-Stapedius tendon } \\
\text {-Separation of IS joint } \\
\text {-Fracture of crura }\end{array}$ & None & ---1-1-1--- & - \\
\hline Chorda tympani & Stretched in 1 patient (1.35\%) & 2nd year & $\begin{array}{l}\text { Asymptomatic } \\
\text { No reported taste disturbance }\end{array}$ \\
\hline $\begin{array}{l}\text { Fenestration of the oval window } \\
\text { (stapedotomy) }\end{array}$ & $\begin{array}{l}\text { Perilymph gush } \\
1 \text { patient (1.4) }\end{array}$ & 3rd year & Leak stopped after placement of prosthesis \\
\hline $\begin{array}{l}\text { Prosthesis insertion: successful 1st } \\
\text { trial insertion in } 65 \text { patients (87.8\%) }\end{array}$ & $\begin{array}{l}\text { Subluxation of incus in } 1 \text { patient } \\
(1.4 \%) \text {; several trials of insertion }\end{array}$ & 1st year & $\begin{array}{l}\text { Cessation of surgery, revised } 6 \text { months later with } \\
\text { successful prosthesis insertion in second surgical } \\
\text { session }\end{array}$ \\
\hline $\begin{array}{l}\text { Anesthesia: local in } 71 \text { patients } \\
(96 \%) \text {, general in } 3 \text { patients (4\%) }\end{array}$ & $\begin{array}{l}\text { Conversion from local to } \\
\text { general in } 1 \text { patient (1.4\%) }\end{array}$ & $\begin{array}{l}1 \mathrm{st}, 2 \mathrm{nd} \text {, and } 3 \mathrm{rd} \\
\text { years, } 1 / \text { year }\end{array}$ & $\begin{array}{l}\text { Two patients were scheduled for general anesthesia } \\
\text { upon their request }\end{array}$ \\
\hline $\begin{array}{l}\text { Revision stapedotomy: one patient, } \\
48 \text { h after 1ry surgery }\end{array}$ & $\begin{array}{l}\text { Displacement of prosthesis off } \\
\text { incus and fenestra }\end{array}$ & 3rd year & $\begin{array}{l}\text { Severe cough and vertigo } 10 \mathrm{~h} \text { after } 1 \text { ry surgery. } \\
\text { Reposition of prosthesis } \\
\text { ABG was closed after revision }\end{array}$ \\
\hline
\end{tabular}

required for instrumentation. However, over removal of the scutum will lead to shortened flap, and this is a potential for retraction pocket and cholesteatoma formation. Section of stapedius tendon, separation of incudostapedial joint, and fracture of the stapes were not associated with a complication.

Chorda tympani was stretched in one patient with no taste affection. Studies support that endoscopic stapedotomy preserves the chorda tympani more than microscopic stapedotomy [16]; absence of taste disturbance in the studied group of patients could be attributed to the relatively small sample size. The theoretical risk of thermal injury to middle ear structures and inner ear by the endoscope is managed by reducing the light power. Insertion of prosthesis is the most difficult part of endoscopic stapedotomy because it is done with a single hand and the

Table 2 Preoperative and postoperative air conduction (AC), air bone gap ( $A B G)$, and gains in $\mathrm{dB}$, across different frequencies: 500, 1000, 2000, and $4000 \mathrm{~Hz}$

\begin{tabular}{|c|c|c|c|c|c|c|}
\hline \multirow{2}{*}{$\begin{array}{l}\text { Frequency } \\
\text { in } \mathrm{Hz}\end{array}$} & \multicolumn{2}{|c|}{ Preoperative } & \multicolumn{2}{|c|}{ Postoperative } & \multicolumn{2}{|c|}{ Gain in $d B$} \\
\hline & $\overline{A C}$ & ABG & $\overline{A C}$ & ABG & $\overline{A C}$ & $A B G$ \\
\hline 500 & 46.9 & 43.7 & 26.4 & 18.0 & 20.5 & 25.6 \\
\hline 1000 & 46.1 & 39.5 & 24.5 & 14.2 & 21.6 & 29.3 \\
\hline 2000 & 41.0 & 25.1 & 25.3 & 9.3 & 15.7 & 15.8 \\
\hline 4000 & 41.1 & 33.0 & 28.2 & 13.2 & 12.9 & 19.8 \\
\hline
\end{tabular}

microscopic technique is superior in this step. Trials of insertion if were not done accurately will lead to the following: subluxation of the incus, this happened to one patient, or slip of the prosthesis into the vestibule with possible cochlear injury.

The advantages of local anesthesia are as follows: It allows communication with the patient during surgery, hence assessment of hearing improvement immediately; the other advantage is that the presence of significant vertigo following prosthesis insertion alerts the surgeon to the possibility of a longer prosthesis; this can be corrected immediately by adjusting the shaft's length. However, keeping the patient still is a real challenge when using local anesthesia; failure to ensure constancy makes general anesthesia an alternative. One patient has a gusher, this was not anticipated preoperatively as there was no history of vertigo; insertion of the prosthesis although was difficult due to profuse perilymph leak succeeded to reduce the leak dramatically. Gelfoam was placed at stapedotomy site after prosthesis insertion, where it was completely sealed and the gusher stopped; the patient was satisfied with hearing improvement and the postoperative PTA showed satisfactory air bone gap closure.

In the revision case, the prosthesis was off the fenestra, yet no sensory element was present in PTA which was purely CHL in the next day of surgery; this could be attributed to the use of vein graft which prevented significant perilymph leak and preserved the cochlea. 
Table 3 Mean air bone gap (ABG) gain after stapedotomy in different studies

\begin{tabular}{llll}
\hline Author & $\begin{array}{l}\text { Country- } \\
\text { year }\end{array}$ & $\begin{array}{l}\text { Number of stapes surgeries studied and technique: microscopic or } \\
\text { endoscopic }\end{array}$ & $\begin{array}{l}\text { Average ABG gain in } \\
\text { dB }\end{array}$ \\
\hline Sarkar et al. [17] & India, 2013 & 32, endoscopic & 31.4 \\
Lin and Selesnick & USA, 2016 & 79, microscopic & 21.21 \\
[18] & & & 17 \\
Alzharani et al. [19] & KSA, 2017 & 45, microscopic & 23.48 \\
Elzayat et al. [20] & Egypt, 2017 & 80, microscopic & 23.4 \\
Xie et al. [21] & China, 2019 & 28, microscopic & 23.3 \\
Current study & Sudan, 2021 & 74 , endoscopic & \\
\hline
\end{tabular}

Audiological assessment of endoscopic stapedotomy patients included ABG at different frequencies, the mean gain was $23.3 \pm 7.2 \mathrm{SD} \mathrm{dB}$, it reflects achievement of this surgical technique in hearing improvement, and the present ABG gain is comparable to other studies as summarized in the Table 3 [17-21].

Middle ear makes a contribution to bone conduction, and correction of a middle ear conductive lesion causes an apparent improvement in inner ear function [22]. In this study, closure of Carhart notch was achieved in the majority (79.5\%). Although most of the operated ears were having $\mathrm{CHL}$ (preoperative mean $\mathrm{BC}$ was $21.5 \mathrm{~dB}$ ) and very few of mixed hearing loss, $\mathrm{BC}$ gain after stapedotomy was statistically significant.

One patient (1.4\%) developed profound sensorineural hearing loss (SNHL). Irreversible profound SNHL is the most disappointing complication of stapedotomy. Stapes surgeons should be aware that injury of the ultra-delicate inner ear structures with permanent sequelae can happen due to excessive mobilization of the stapes during foot plate fenestration, transmission of microdrill vibrations, displacement of prosthesis shaft into the vestibule, bleeding into the vestibule, and direct trauma to inner ear structures by instruments; this can lead to rupture of Reissner's membrane, which is composed of two layers separating the endolymphatic space from the perilymphatic space; a torn Reissner's membrane causes the cochlear action potential to drop drastically [23]. Modern stapes surgery is still evolving, and laser has become the tool of choice to create an opening in the footplate that is small enough to fit a piston prosthesis and reduce excessive mobilization of the stapes, hence reduce injury to the vestibule [14], avoidance of microdrill and clear surgical field are factors that should be considered to reduce the incidence of SNHL.

Factors that affect tinnitus improvement are preoperative AC, ABG, and postoperative AC [24]. In this study tinnitus improved in only $21.5 \%$ which is lower than reported by other studies [25]; this could be related to the higher percentage of preoperative tinnitus reported in our series; tinnitus being subjective needs careful assessment before and after surgery; further detailed study is required to verify tinnitus.

\section{Conclusions}

Otosclerosis in the 91 studied patients affects females slightly more than males, mean age of presentation is $30.6 \pm 7$ SD years, all patients complained of hearing loss, it has a relatively high percentage of tinnitus $(88 \%)$, and only $2.2 \%$ had vertigo. Family history was reported in $2.2 \%$. CHL was reported in $81.3 \%$ ears and mixed type in $16.5 \%$ ears.

Endoscopic stapedotomy was performed for 74 patients; the procedure has a steep learning curve and was associated with few complications that were managed successfully, e.g., one gusher and one was revision. No taste disturbance was observed.

Hearing results were excellent as the mean ABG gain was $23.3 \mathrm{~dB}, \mathrm{AC}$ gain was $18.3 \mathrm{~dB}$, Carhart notch disappeared in $79.5 \%$, and a statistically significant $\mathrm{BC}$ gain was reported.

\section{Abbreviations}

PTA: Pure tone audiogram; AC: Air conduction; BC: Bone conduction; ABG: Air bone gap; CHL: Conductive hearing loss; SNHL: Sensorineural hearing loss; SD: Standard deviation

\section{Acknowledgements \\ Not applicable}

\section{Authors' contributions}

NEA made substantial contribution in conception, design, analysis, interpretation of data, and drafting. TAN made substantial contribution in conception, design, analysis, interpretation of data, and revision of the manuscript draft. AFM made substantial contribution in conception, design, data acquisition, analysis, and interpretation of data. AAA made substantial contribution in conception, design, data acquisition, analysis, and interpretation of data. HIY made critical revision of the manuscript draft. AMA made substantial data interpretation and revision of the manuscript draft. The authors read and approved the final manuscript

\section{Funding}

The authors received no financial support for the research and/or authorship of this article.

Availability of data and materials

All data generated or analyzed during this study are included in this published article. Data sharing is not applicable to this article as no datasets were generated or analyzed during the current study. 


\section{Declarations}

\section{Ethics approval and consent to participate}

Ethical clearance was obtained from the Research Committees of both ENT Khartoum Teaching Hospital and Aldoha Specialized ENT Hospital with no reference number being allocated for both. Patients are informed verbally about the study and signed an informed consent to participate in this study.

\section{Consent for publication}

Not applicable

\section{Competing interests}

The authors declare that they have no competing interests.

\section{Author details}

'Department of Otorhinolaryngology H\&N Surgery, Faculty of Medicine, University of Khartoum, P O Box102, Qasr Street, Khartoum, Sudan. ${ }^{2}$ ENT Khartoum Teaching Hospital, Qasr street, Khartoum, Sudan. ${ }^{3}$ Aldoha Specialised ENT Hospital, Mohamed Najeeb street, Khartoum, Sudan.

Received: 19 May 2021 Accepted: 2 July 2021

Published online: 03 August 2021

\section{References}

1. Browning GG, Gatehouse S (1984) Sensorineural hearing loss in stapedial otosclerosis. Ann Otol Rhinol Laryngol 93(1):13-16. https://doi.org/10.1177/ 000348948409300104

2. Ramsay HA, Linthicum FH Jr (1994) Mixed hearing loss in otosclerosis: indication for long-term follow-up. Am J Otolaryngol 15(4):536-539

3. Declau F, van Spaendonck M, Timmermans J-P (2007) Prevalence of histologic otosclerosis: an unbiased temporal bone study in Caucasians. Adv Otorhinolaryngol 65:6-16. https://doi.org/10.1159/000098663

4. Cureoglu S, Baylan MY, Paparella MM (2010) Cochlear otosclerosis. Curr Opin Otolaryngol Head Neck Surg 18(5):357-362. https://doi.org/10.1097/ MOO.0b013e32833d11d9

5. Skarzynski PH, Dziendziel B, Gos E et al (2019) Prevalence and severity of tinnitus in otosclerosis: preliminary findings from validated questionnaires. J Int Adv Otol 15(2):277-282. https://doi.org/10.5152/iao.2019.5512

6. Menger DJ, Tange RA (2003) The aetiology of otosclerosis: a review of the literature. Clin Otolaryngol Allied Sci 28(2):112-120. https://doi.org/10.1046/ j.1365-2273.2003.00675.x

7. Souza JC, Bento RF, Pereira LV et al (2016) Evaluation of functiona outcomes after stapes surgery in patients with clinical otosclerosis in a teaching institution. Int Arch Otorhinolaryngol 20:39-42

8. Declau F, Van Spaendonck M, Timmermans JP et al (2001) Prevalence of otosclerosis in an unselected series of temporal bones. Otol Neurotol 22(5): 596-602. https://doi.org/10.1097/00129492-200109000-00006

9. Adv Otorhinolaryngol. Basel, Karger (2011) Medical genetics in the clinical practice of ORL. In: Alford RL, Sutton VR (eds), vol 70, pp 1-9

10. Batson L, Rizzolo D (2017) Otosclerosis: an update on diagnosis and treatment. J Am Acad Physician Assist 30(2):17-22. https://doi.org/10.1097/ 01.JAA.0000511784.21936.1b

11. Mosnier I, Bouccara D, Ambert-Dahan E, Ferrary E, Sterkers O (2007) Cochlear implantation and far-advanced otosclerosis. Adv Otorhinolaryngol 65:323-327. https://doi.org/10.1159/000098854

12. Hancı D, Sözen T, Kayahan B et al (2014) Stapes surgery outcomes: the practice of 35 years. Turk Arch Otolaryngol 52(4):115-120. https://doi.org/10. 5152/tao.2014.516

13. Fisch U (1982) Stapedotomy versus stapedectomy. Am J Otolaryngol 4(2): 112-117

14. Nazarian R, McElveen JT Jr, Eshraghi AA (2018) History of otosclerosis and stapes surgery. Otolaryngol Clin N Am 51(2):275-290. https://doi.org/10.1016/ j.otc.2017.11.003

15. Tarabichi M (2010) Endoscopic transcanal middle ear surgery. Indian J Otolaryngol Head Neck Surg 62(1):6-24. https://doi.org/10.1007/s12070-0100007-7

16. Moneir W, Abd El-Fattah AM, Mahmoud E et al (2018) Endoscopic stapedotomy: merits and demerits. J Otolaryngol 13(3):97-100. https://doi. org/10.1016/j.joto.2017.11.002
17. Sarkar S, Banerjee S, Chakravarty S, Singh R, Sikder B, Bera SP (2013) Endoscopic stapes surgery: our experience in thirty-two patients. Clin Otolaryngol 38(2):157-160. https://doi.org/10.1111/coa.12051

18. Lin KF, Selesnick S (2016) Stapedotomy with adipose tissue seal: hearing outcomes, incidence of sensorineural hearing loss, and comparison to alternative techniques. Otol Neurotol 37(7):851-858. https://doi.org/10.1097/ MAO.0000000000001117

19. Alzhrani F, Baqays A, Almutawa H (2017) Stapes surgery using stapedotomy versus partial stapedectomy. Otolaryngol (Sunnyvale) 7(1):291

20. Elzayat S, Younes A, Fouad A, Erfan F, Mahrous A (2017) Hearing outcome with the use of glass ionomer cement as an alternative to crimping in stapedotomy. Otol Neurotol 38(9):1240-1245. https://doi.org/10.1097/MAO 0000000000001564

21. Xie J, Zhang LJ, Zeng N, Liu Y, Gong SS (2019) The clinical characteristics of otosclerosis and benefit from stapedotomy: our experience of 48 patients (58 ears). Acta Otolaryngol 139(10):843-848. https://doi.org/10.1080/000164 89.2019 .1649459

22. Vijayendra H, Parikh B (2011) Bone conduction improvement after surgery for conductive hearing loss. Indian J Otolaryngol Head Neck Surg 63(3):201204. https://doi.org/10.1007/s12070-011-0130-0

23. Souza C, Glasscock M (2014) Otosclerosis and stapedectomy diagnosis, management, and complications. Thieme

24. Sobrinho PG, Oliveira CA, Venosa AR (2004) Long-term follow-up of tinnitus in patients with otosclerosis after stapes surgery. Int Tinnitus J 10(2):197-201

25. Cavalcante AMG, de Castro Silva IM, Neves BJ et al (2018) Degree of tinnitus improvement with stapes surgery - a review. Braz I Otorhinolaryngol 84(4): 514-518. https://doi.org/10.1016/j.bjorl.2017.12.005

\section{Publisher's Note}

Springer Nature remains neutral with regard to jurisdictional claims in published maps and institutional affiliations.

\section{Submit your manuscript to a SpringerOpen ${ }^{\circ}$ journal and benefit from:}

- Convenient online submission

- Rigorous peer review

- Open access: articles freely available online

High visibility within the field

- Retaining the copyright to your article

Submit your next manuscript at $\boldsymbol{\nabla}$ springeropen.com 